\title{
Sharing New Knowledge: A Review of Dissemination Rates and Journal Emphasis in Career and Technical Education
}

\author{
Victor M. Hernandez-Gantes \\ University of South Florida
}

\begin{abstract}
In career and technical education (CTE), the role of academic journals has been critical in the dissemination of information as the field shifted from vocational education to CTE. To keep up with changes in the field, some journals have been renamed to reflect the new emphasis, other journals have retained their historical branding, and new journals have emerged. Thus, the purpose of this descriptive research was to review the typology and dissemination rates of journals currently available in CTE as a means to clarify their role and impact in the field. The review resulted in the identification of 17 journals mediating the diffusion of research information in the United States and internationally. Further, over the past 10 years (2008-2017), a consistent rate of dissemination was observed as a whole, but variable for individual journals. In general, considering the overall pool, scope, and emphasis relevant to different audiences, it appears that journals in the field represent a consistent diffusion model to make research information readily accessible for a variety of purposes.
\end{abstract}

Keywords: career and technical education, vocational education and training, academic journals, diffusion of research information

\section{Introduction}

The role of scholarly journals has been well documented regarding the dissemination of research information in particular fields. To be sure, journal readers want to keep abreast of new research results, identify directions for further research, draw potential applications to practice and teaching, or to document support for project proposals (Tenopir, 2003). It has been also reported that the primary and most consistent method for identifying journal articles is online browsing of recently published issues, followed by reviewing citations in publications (Tenopir \& King, 2000). In this regard, over the past decade, online sources have become the predominant platform for dissemination of information and making archival literature readily available. As such, most scholarly journals are now available online, which has increased the relevance of online browsing and searching for scholarly information (Brownson, Eyler, Harris, Moore, \& Tabak, 2018; Tenopir, King, Edwards, \& Wu, 2009).

In career and technical education (CTE), the role of scholarly journals has been critical in the dissemination of information over the past three decades, as the field evolved from the prior nametag of "vocational education" (Hernandez-Gantes, 2016; Gordon, 2014). To keep up with changes in the field, some journals have been renamed to reflect the new emphasis, other journals have retained their historical branding, and new journals have emerged. The common denominator to all journals in the field is the universal availability in electronic format, which is now essentially the norm in scholarly dissemination of information (Brownson et al., 2018; Lawrence, 2001; Tenopir et al., 2009).

When discussing the role of scholarly journals in a particular field, the issue of impact factors has become more prominent in recent years (Garfield, 2006; Oermann \& Shaw-Kokot, 2013). While a journal's ranking in a publication such as Journal Citation Reports serves as a proxy of overall quality, in a small field such as CTE, there is not enough citation traffic for inclusion on the analytics of citation reports (Flanagan, 2013; Oermann \& Shaw-Kokot, 2013). Instead, other indicators such as publication consistency, peer review process, and reach to intended audience should be taken into consideration (Flanagan, 2013; King \& Tenopir, 2001; Vogela, Hattke, \& Petersen, 2017). In a small field, existing journals must compete for a limited number of submissions and ensure consistent editorial support and peer reviewing to keep publication production at predictable rates (Brownson et al., 2018; Rojewski \& Domenico, 2004; Solomon, 2007). Further, the emphasis of publications is also important to ensure that new knowledge is reaching the intended audience (Brownson et al., 2018; King \& Tenopir, 2001; King, Tenopir, Hansen Montgomery, \& Aerni, 2003). Thus, in the field of CTE, historically rooted in the trades but currently embracing a broader preparation for careers and interdisciplinary academic connections, the current 
research asks how are journals disseminating scholarly information? What is the emphasis of current journals, and what are the trends in dissemination rates?

To address these questions, the purpose of this article was to review the typology and dissemination rates of journals currently available in CTE as a means to clarify their role and impact in the field.

Conceptual Perspectives and Framework. The goal of conducting research in any field is to have an impact on improved practices, processes, and products. To meet this goal, there is an ongoing quest to reduce the gap from research to practice, with scholarly journals serving as the mediating vehicle (Brownson et al., 2018). In order to provide contextual background for this article, the role of journals in the dissemination of research information and a model for dissemination are reviewed and discussed.

Role of Scholarly Journals in the Dissemination of Research Information. Reducing the researchpractice gap is a universal goal in all disciplinary contexts including education. While researchers engage in knowledge production and attempt to contribute new knowledge in particular fields, the actual impact of research is directly tied to reaching its intended audiences (Ware \& Mabe, 2015). In this regard, the role of scholarly journals represents a critical catalyst because they are designed to act as active channels for dissemination and ensure a consistent flow of information to specific audiences (Schaffner, 1994; Tenopir \& King, 2000). As such, timely and predictable dissemination of research information is important in a field, and can represent an indicator of journal quality (Herie \& Martin, 2002; McGuigan \& Russell, 2008).

In recent years, the majority of scholarly journals have embraced electronic means to ensure anytimeanywhere access to research information (Lawrence, 2001). This has resulted in the ability to produce electronic copies of whole issues and single articles, reduce the time for publication after the review process, and reach audiences faster compared to the traditional paper-based model (Tenopir et al., 2009). Journals in the field of CTE have followed suit in making new issues available online. However, the underlying production process has remained essentially the same and tied to lingering issues associated with the role of the editor, editorial board, and peer-review quality that have been addressed in the literature (McGuigan \& Russell, 2008; Ware \& Mabe, 2015). These issues appear to be of interest in many disciplinary contexts, and have been discussed in CTE as well (Rojewski \& Domenico, 2004; Tenopir, 2003).

Although electronic dissemination is now the norm, the overall quality of a journal production process can have an impact on the rate of dissemination. For example, journals with editors serving only one- or two-year appointments may experience lags in production processes and dissemination timelines as new editors catch up with the new responsibilities (McGuigan \& Russell, 2008). Issues with the peer-review process may also contribute to the rate of dissemination (Rojewski \& Domenico, 2004; Solomon, 2007). The combination of these and other factors may cause, in some instances, a gap in the publication of an issue or even making a journal inactive for a year or two. Thus, the steady release of research information can be used as an indicator of journal quality based on its reliable and predictable dissemination process (Flanagan, 2013; King \& Tenopir, 2001).

Another issue often encountered by researchers is the question of where to publish. Although this question may be taken as naïve, it is not always evident what may be the most appropriate journal fit for the submission of a manuscript (Brownson et al., 2018). In some cases, a journal emphasizing broader applications in a field may not be a good fit for a manuscript featuring research results in a disciplinary area where the intended audience is more narrow. On the other hand, there are cases where a research manuscript may be in the periphery of a journal's emphasis areas and may be best suited for submission to a journal in another discipline. In both cases, the author attempts to understand a journal's emphasis as a means of identifying and reaching the intended audience (McGuigan \& Russell, 2008). Once a manuscript is submitted to a journal it is the job of the editor to determine the fit with the journal emphasis and potential interest to the readership (i.e., the intended audience) (Rojewski \& Domenico, 2004; Solomon, 2007; Ware \& Mabe, 2015).

Model for Dissemination of Research. In the midst of an ongoing discussion about academic journal quality, it has been suggested to look for alternative indicators of performance beyond impact factors that rely heavily on citation rates (Flanagan, 2013; Garfield, 2006; Vogela et al., 2017). This is relevant for small journals, as in the case of journals in CTE, which are often disadvantaged in terms of impact factor due to their low volume of production relative to mainstream journals. In this context, since the consistent dissemination of research information is at the core of the process for reaching intended audiences, examining the rate of dissemination by journals in CTE can represent an alternative indicator of performance.

In order to better understand the role of scholarly journals in the dissemination of research information, it is important to understand the underlying communication process, taking a cue from applications across disciplinary fields (Brownson et al., 2018). Diffusion of innovation theory has provided the basis for understanding the process for communicating new ideas using various information channels (Rogers, 2003). At the core of diffusion of innovation theory is innovation information, construed as new ideas or practices deemed to have potential impact in areas of interest. In turn, new ideas require communication channels to funnel information to target audiences. Over time, the adoption of new information may vary from early to late consideration depending on the audience. As such, the fourth element of the diffusion theory is consideration for 
a social system, whereby new ideas are generated and channeled through organized efforts and common goals (Kaminski, 2011; Rogers, 2003).

Drawing from diffusion of innovation theory, a communication model for the diffusion of research information has been used widely in a variety of fields including education (Brownson et al., 2018; Green, Ottoson, Garcia, \& Hiatt, 2009). At the center of the model, originally developed by Weaver and Shannon (1963), is consideration of the message, highlighting the importance of the research information to be disseminated. That is, a key attribute of research information (the message) is the potential value for improving or understanding existing practices. Another feature of the model is the rate of information associated with the message to ensure reaching the intended target audience. Further, information research has to be channeled through purposeful and active sources, which in academia is typically mediated by scholarly journals. In this case, although other sources are also used, peerreviewed journals are often seen as the primary source of vetted research information given their underlying review process. As such, an understanding of the target audience is also an essential component of the model to reach broad disciplinary groups as well as segments of a larger network (Brownson et al., 2018; Weaver \& Shannon, 1963). The idea of targeting specific segments of a population has been an effective strategy for dissemination purposes that also applies to the communication of research information (Rogers, 2003).

Building on diffusion of innovation theory and the model developed by Weaver and Shannon (1963), this author developed the model outlined in Figure 1 to guide the conceptualization of the descriptive research and interpretation of results in the context of CTE.

In this model, the message (research information) is at the center of the process, with particular emphasis on the rate of dissemination. The rate of communication has been identified as a key feature of information channels to sustain systematic diffusion of new ideas (Rogers, 2003; Tenopir et al., 2009). As such, the rate of information dissemination (information rate) is considered an important feature of an active process that helps translate research into usage by intended audiences (Lawrence, 2001). In turn, the source component, for the purpose of the descriptive review, is associated with the type of journal catalyzing the dissemination of information. As the field has evolved from vocational to career and technical education, existing journals have remained closely tied to particular groups within the broader field; some journals have been renamed to reflect the broader interests, while others feature even broader connections to other relevant disciplines. Thus, accounting for the type of journal emphasis is a consideration that is also relevant to the intended audience (Brownson et al., 2018; King \& Tenopir, 2001). In the field of CTE, audiences may include researchers interested in broader disciplinary topics (e.g., integration of technical and academic education, programs of study, transitions); researchers and practitioners seeking information in specific disciplinary topics (e.g., agricultural education, business education); policymakers looking for information with broader implications; and other professionals in the field. In addition, time is another important consideration as an indicator of an active dissemination process established and sustained by journals in the field (Tenopir, 2003). That is, the rate of dissemination over time should remain relatively steady to ensure systematic and predictable access to research information.

Based on these conceptual perspectives and model, I identified journals in the field of CTE and examined their publication emphasis and rate of dissemination information over the 10-year period from 2008 to 2017.

\section{Method}

Descriptive research represented the underlying approach to data collection and analysis. Descriptive research may involve the documentation of quantitative information to be described in meaningful patterns and trends, which aligns with the purpose of journal data review and tabulation (Creswell, 2018; Loeb et al., 2017). In this case, the purpose was to review the typology and dissemination rates of journals in CTE to clarify their role and impact in the field in terms of research information dissemination.

Research Questions. Three research questions were used to guide data collection and analysis. The first research question was: What are the journals currently available online in career and technical education? The

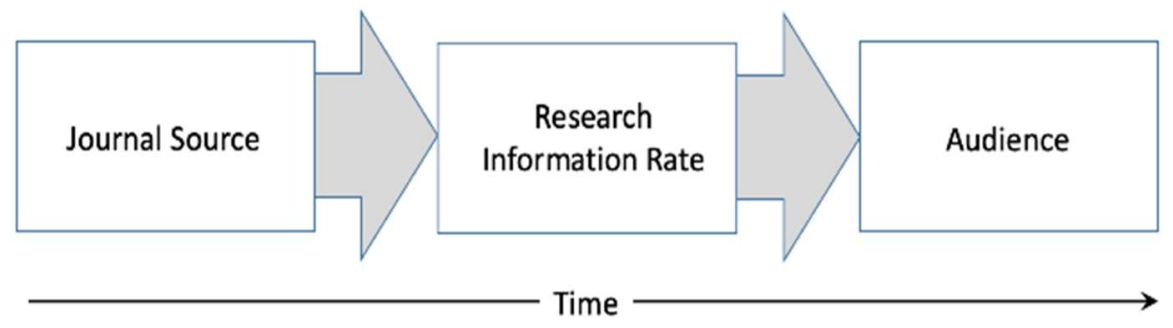

Figure 1. Model for Dissemination of Research 
initial question was designed to identify the pool of active scholarly journals in the field of CTE that are available online in the United States and internationally. Regarding journals published abroad, it is important to note that in Europe and elsewhere in the world, practitioners still refer to the field as vocational education and training. The second question was: What is the topical publication emphasis of journals in the field? The intent of this question was to drive data collection and descriptive analysis of each journal's publication emphasis in terms of topical focus and target audiences. The third question was: What are the annual publication trends of journals in the field? The goal of the last question was to organize publication data and describe publication trends over a period of ten years (2008-2017), focusing on the rate of dissemination.

Journal Search Strategy and Data Collection. The identification of journals in the field was based on disciplinary alignment with CTE. Regarding geographical scope, I included journals published in the United States and abroad. Outside of the United States, European journals have historically served as the most prominent sources of research information in the field internationally. Regarding disciplinary alignment, I targeted journals in the field featuring articles related to CTE and vocational education and training. While the term career and technical education is used primarily in the United States, vocational education and training is still used elsewhere in the world (Hernandez-Gantes, 2016). I also identified journals that publish articles in disciplinary areas that have been historically aligned with CTE in the United States, such as agricultural education, business education, and technology education.

Queries were conducted through a university library using six database indexing engines/repositories including ERIC, Cabells Scholarly Analytics, Journal Storage (JSTOR), Directory of Open Access Journals (DOAJ), International Scientific Indexing (ISI), and Science Direct. Only journals that are currently active and available online were selected for review and analysis, including journals that have been active for decades and have evolved in terms of name, and journals that have been founded in recent years. Once a journal was identified for inclusion in the review and analysis, I visited electronic sites to verify the availability of background information and archival data for the period of 2008-2017. This period was chosen to get a glimpse of recent trends over a decade of publication output in the field.

Analysis. Upon identification of journals in the field of CTE, journals were reviewed in terms of their topical publication emphasis to determine an organizational typology. The journals were initially organized based on their general scope in CTE in the United States and in vocational education and training internationally. Next, a secondary review was conducted to sort journals by topical emphasis, from broad applications in the field to disciplinary focus within the field (e.g., agricultural education, business education). Finally, the analysis of journal publication data consisted of tabulation of number of issues and articles per year for the 10-year period from 2008 to 2017. Again, the period for review was selected to ensure recent publication data and online access to archived publications, and a decade of information to identify publication trends. The rate of dissemination information was analyzed based on the total number, average, and percentage of issues and articles over the ten-year period and per year.

\section{Results}

Sorting Out the Journals in the Field. To address the question about journals currently available online in CTE, it was important to define the term. Formerly referred to as "vocational education" in the United States, "career and technical education" is a term applied to formal education delivered in secondary and

Table 1. Initial List of Journals by National and International Scope

\begin{tabular}{|l|l|}
\hline National Scope: United States & International Scope \\
\hline Career and Technical Education Research (CTER) & $\begin{array}{l}\text { International Journal of Adult Vocational Education \& } \\
\text { Technology (IJAVET) }\end{array}$ \\
\hline $\begin{array}{l}\text { Community College Journal of Research and Practice } \\
\text { (CCJRP) }\end{array}$ & $\begin{array}{l}\text { International Journal for Research in Vocational } \\
\text { Education and Training (IJRVET) }\end{array}$ \\
\hline $\begin{array}{l}\text { Family and Consumer Sciences Research Journal } \\
\text { (FCSRJ) }\end{array}$ & $\begin{array}{l}\text { International Journal of Vocational and Training } \\
\text { (IJVET) }\end{array}$ \\
\hline Journal of Agricultural Education (JAE) & Journal of Education and Work (JEW) \\
\hline Journal of Career and Technical Education (JCTE) & Journal of Technical Education (JOTED) \\
\hline Journal of Research in Business Education (JRBE) & Journal of Vocational Education and Training (JVET) \\
\hline Journal of Research in Technical Careers (JRTC) & Vocations \& Learning (V\&L) \\
\hline Journal of Technology Education (JTE) & \\
\hline $\begin{array}{l}\text { Online Journal for Workforce Education and } \\
\text { Development (OJWED) }\end{array}$ & \\
\hline Workforce Education Forum (WEF) & \\
\hline
\end{tabular}


postsecondary settings through programs for youth and adults in high-wage, high-skill, high-demand careers (Great Schools Partnership, 2014; Association for Career and Technical Education, 2018). Based on queries using indexing source, 45 journals were initially identified using terms such as "career and technical education," "vocational education," and "vocational education and training." Upon checking current availability and online access, the list was reduced to 43 journals, with 26 publications broadly connected to CTE in the United States, and 17 associated with vocational education and training internationally.

However, the initial list was too broad and included journals that were relevant, but not directly connected to CTE. For example, multiple disciplines were represented in the initial pool of journals, with many of those journals serving as outlets for dissemination targeting audiences in other specific fields such as adult education, human resources, and career development. In general, those journals represent fields that are typically found in university programs on their own, separate from CTE. Additionally, other journals are interested in interdisciplinary connections (e.g., adult education and human resources) ancillary to CTE. Thus, based on a secondary review of direct alignment with CTE in the United States and vocational education and training internationally, the initial list was reduced to a total of 27 journals (Table 1).

The final list includes 10 publications in the United States and seven international publications. The list representing journals in the field is by no means exhaustive as there may be other journals disseminating related information. To clarify, the journals identified here met the criteria for inclusion involving availability online, direct CTE disciplinary relevance, and primary mission of dissemination of research information.

Disciplinary Emphasis and Scope. In the United States, CTE is formally implemented in secondary and postsecondary institutions. In high schools, the focus is on preparation for careers in high-wage, high-skill, highdemand careers, while in community colleges the emphasis is on technician preparation. School programs also provide career preparation for at-risk youth and adults requiring some form of systematic career/vocational education and training. Given this context, in the United States, the avenues for dissemination of related research have been represented by journals with foci associated with issues and research related to the field as a whole, specific disciplines within the field, and broader implications to workforce education and training. Internationally, the field has remained grounded in vocational education and training, with journals providing holistic dissemination of research information from varying perspectives.

Based on these premises, I reviewed the mission and scope of each journal listed in Table 1 to determine its direct disciplinary alignment with career and technical education (and vocational education). As reported in Table 2, among U.S. journals, three journal sources were

Table 2. List of Journals in the Field by Disciplinary Emphasis and Electronic Address

\begin{tabular}{|c|c|}
\hline Journal Emphasis/Scope & Electronic Address \\
\hline \multicolumn{2}{|l|}{ CTE Disciplinary Emphasis } \\
\hline - Career and Technical Education Research & http://www.ingentaconnect.com/content/acter/cter \\
\hline - Journal of Career and Technical Education & https://journalcte.org \\
\hline - Journal of Research in Technical Careers & https://digitalscholarship.unlv.edu/jrtc \\
\hline \multicolumn{2}{|l|}{ Disciplinary Emphasis } \\
\hline - Family and Consumer Sci. Research Journal & https://onlinelibrary.wiley.com/journal/15523934 \\
\hline - Journal of Agricultural Education & http://jae-online.org \\
\hline - Journal of Research in Business Education & $\begin{array}{l}\text { https://www.questia.com/library/p438572/the-journal- } \\
\text { of-research-in-business-education }\end{array}$ \\
\hline - Journal of Technology Education & https://scholar.lib.vt.edu/ejournals/JTE/ \\
\hline \multicolumn{2}{|l|}{ CTE/Workforce Emphasis } \\
\hline - Community College Journal of Res. \& Practice & https://www.tandfonline.com/toc/ucjc20/current \\
\hline - Online Journal for Workforce Ed. \& Dev. & https://opensiuc.lib.siu.edu/ojwed/ \\
\hline - Workforce Education Forum & http://journals.sfu.ca/wef/index.php/wfed/index \\
\hline \multicolumn{2}{|c|}{ International/Vocational Education and Training Emphasis } \\
\hline - Int'l Journal for Res. in Voc. Ed. \& Training & http://www.ijrvet.net/index.php/IJRVET \\
\hline $\begin{array}{l}\text { - International Journal of Adult Vocational Ed. \& } \\
\text { Technology }\end{array}$ & $\begin{array}{l}\text { http://www.igi-global.com/journal/international-journal- } \\
\text { adult-vocational-education/1131 }\end{array}$ \\
\hline - International Journal of Voc. and Tech. Ed. & http://www.academicjournals.org/journal/IJVTE \\
\hline - Journal of Education and Work & https://www.tandfonline.com/loi/cjew20 \\
\hline - Journal of Technical Education & $\begin{array}{l}\text { http://www.journal-of-technical- } \\
\text { education.de/index.php/joted/index }\end{array}$ \\
\hline - Journal of Vocational Education and Training & https://www.tandfonline.com/loi/rjve20 \\
\hline - Vocations \& Learning & https://link.springer.com/journal/12186 \\
\hline
\end{tabular}


identified as having a CTE interdisciplinary emphasis, four representing a disciplinary emphasis, and three featuring an emphasis connecting CTE and workforce issues in general. Each of the international journals reflect a broad but consistent emphasis in vocational education and training.

CTE interdisciplinary emphasis. As the field of vocational education took its roots into different disciplines, two journals emerged with a holistic interdisciplinary focus relevant to all constituencies independent of disciplinary trades during the second half of the twentieth century. Career and Technical Education Research (CTER) is the official publication of the Association for Career and Technical Education Research (ACTER), a professional association for scholars and others with interests in CTE. CTER was founded in 1966 and initially published as the Journal of Vocational Education Research (JVER). In turn, Journal of Career and Technical Education (JCTE), is the official publication of Omicron Tau Theta, a national graduate honorary society in CTE, and serves as a forum for dissemination of research, and discussion of philosophy, theory, practice, and issues in CTE. JCTE was initially published as the Journal of Vocational and Technical Education (JVTE) from 1985 through 1999. Under its current name, the journal is published online with free access for audiences interested in CTE. In the United States, these two journals have represented the two premier journals in the field now referred to as CTE.

In 2017, a new journal with a holistic and interdisciplinary emphasis was established to expand the channels for dissemination of research in the field. Journal of Research in Technical Careers (JRTC) is an open-access, peer-reviewed journal, "intended to stimulate and disseminate scholarly activity on critical issues" relevant to the disciplines represented in CTE at the secondary and post-secondary level (Gordon \& Godbey, 2017). JRTC is published by the Department of Teaching and Learning at the University of Nevada, Las Vegas, and makes its holistic and interdisciplinary emphasis a key journal feature. Thus, the journal calls for submissions related to any of the 16 career clusters in the National Career Clusters Framework (Gordon \& Godbey, 2017).

In general, these three journals reflect the new developments in the field and the shift to CTE. As such, CTER and JCTE are the two flagship journals in the field with editors and editorial board typically engaged in the dissemination of research information through the national Association for Career and Technical Education Research (ACTER). The editors and editorial board of JRTC are also engaged members in ACTER and, collectively, these journals clearly represent an interest in the dissemination of research information relevant to all disciplinary groups in CTE.

Disciplinary emphasis. The historical roots of publications in the field are grounded in the primary disciplines of vocational education in the United States, including agriculture, business, industrial arts, and home economics education. Sponsored by the American Home Economics Association, Journal of Home Economics is the oldest journal of record in the field, published from 1909 through 1993. Since 1972, as the discipline evolved into family and consumer sciences, the Family \& Consumer Sciences Research Journal has been the flagship publication of the American Association of Family \& Consumer Sciences (AAFCS). AAFCS is the national professional association dedicated to improving the work of family and consumer sciences professionals and practitioners. As such, FCSRJ's emphasis is on disseminating research information related to consumerism, human development, and family studies to housing, technology, nutrition, and textiles.

Journal of Agricultural Education (JAE) was established in 1961 as the Journal of the American Association of Teacher Educators in Agriculture, with the first two issues published in mimeograph format. The journal evolved from a monthly magazine, The Agricultural Education Magazine, endorsed by the American Vocational Association, first published in 1929 , and is still in operation published by the National Association of Agricultural Educators. The name of the journal was changed to Journal of Agricultural Education in 1989, and has been fully available in electronic format since 2011. The journal is the official publication of the American Association for Agricultural Education, and its emphasis is on the dissemination of research information and discussion of trends and innovations in the profession.

Journal of Research in Business Education (JRBE) is another publication rooted in the historical disciplines representing vocational education in the past and CTE today. The oldest publication in this discipline is the Business School Journal initially published in 1928 as the Journal of Business Education from 1929 to the present. However, the current focus and scope of the journal has shifted to issues relevant to professional and college applications, and was therefore excluded from this study. As such, JRBE, originally published as the Delta P $i$ Epsilon Journal from 1992 to 2012, is the primary journal featuring a research emphasis relevant to CTE. JRBE is one of the flagship journals of the National Business Education Association (NBEA), and its emphasis is on research related to improving business education programs and/or business teacher education programs.

In addition, Journal of Technology Education (JTE) is another disciplinary journal serving as a dissemination channel for research information and discussion of issues relevant to technology and engineering-related education. JTE was established in 1989 to complement dissemination of Journal of Industrial Teacher Education (JITE), sponsored by the National Association of Industrial Teacher Educators and representing one of the pillars of vocational education groups. JITE's publication was initiated in 1964, but it was discontinued in 2010 as the field was in transformation. At that time, the journal was renamed as the Journal of sTEm Teacher Education to focus on a broader audience interested in technology 
applications beyond CTE. As such, JTE, which is cosponsored by the International Technology Education Association and the Council on Technology Teacher Education, has continued to represent one of the major audiences within CTE.

CTE/workforce emphasis. A third set of journals in the field represent the interface of CTE and workforce issues with implications for secondary and postsecondary education. In this case, over the past two decades, the role of community colleges in technician preparation has been highlighted by policymakers and is an example of CTE/workforce connections (Bailey, Smith Jaggars, \& Jenkins, 2015). In turn, CTE now calls for greater transitional integration between secondary and postsecondary education through articulation agreements, career pathways, and dual enrollment. As such, Community College Journal of Research and Practice (CCJRP) offers a channel for dissemination of related research. There are other journals such as Community College Review and Community College Journal, but their emphasis is on administrative and broad college functions or on periodical discussion of comprehensive community college issues. CCJRP was established in 1976 as the Community Junior College Research Quarterly, was renamed in 1982 as the Community Junior College Research Quarterly of Research and Practice and remained in operation under that name through 1992. Since 1993, CCJRP has provided a multidisciplinary forum with an emphasis on the role community colleges play locally and nationally.

Online Journal for Workforce Education and Development (OJWED) is another journal representing $\mathrm{CTE} /$ workforce connections and implications to practice. OJWED was established in 2005 as a peer-reviewed publication produced by the Department of Workforce Education and Development at Southern Illinois University Carbondale. The goal was to offer a channel for dissemination of research information through open access, and as a means to stimulate discussion on critical issues in workforce, career, and technical education, including training and development. Similarly, Workforce Education Forum (WEF), often referred to as the Forum, is a peer-reviewed journal with the mission to disseminate research information in workforce development and CTE. The Forum is sponsored and produced by the Professional Personnel Development Center (PPDC) in the Workforce Education and Development Program at Penn State university. The Forum was established in 1971 as the Occupational Education Forum by the Alpha (Penn State) Chapter of Iota Lambda Sigma (ILS), the Professional Industrial Education Fraternity. Journal editorial leadership has been rooted in the graduates of industrial, vocational, or workforce education programs at Penn State.

International/vocational education and training emphasis. Internationally, seven journals were identified, all sharing a sustained identification with vocational and training as previously embraced in the United States. In this category, the Journal of Vocational Education and
Training (JVET) is a peer-reviewed journal with an emphasis on the discussion of research and implications to policy and practice in the field from a variety of disciplinary and inter-disciplinary perspectives. The journal is particularly interested in research conducted in different settings where vocational and training is offered and the connections to curriculum, pedagogy, and assessment, as well as economic, cultural and political aspects related to the role of vocational and professional education and training in society. JVET was first established as the Vocational Aspect of Education in 1948 and has been published under the current name since 1996. Similarly, Vocations and Learning: Studies in Vocational and Professional Education is a peerreviewed journal with an emphasis on research that informs the broad field of vocational and professional learning in a variety of institutional settings. Vocations and Learning has been published since 2008.

Additionally, Journal of Education and Work (JEW) initiated publication production in 1987 under the name of British Journal of Education and Work and has been published under its current name since 1997. The journal emphasis is on research derived from the study of how knowledge, skills, values and attitudes both about and for work and employment are promoted in schools. Journal of Technical Education (JOTED) is another international channel for dissemination of research information established in 2013. JOTED's emphasis is on research related to technical and applied technology education of interest to scientists and teachers and is published in German and English. Along these lines, International Journal of Adult Vocational Education and Technology (IJAVET) was established in 2010 to disseminate information related to educational technologies for adult learners in the context of teaching, learning, research, and practice, and as a means to produce further insights on the interplay of CTE, adult education, and technology.

Two additional journals, sponsored by professional organizations in the field, are also disseminating research information internationally. International Journal of Vocational Education and Training (IJVET) was established in 1993 as the official refereed publication of the International Vocational Education and Training Association (IVETA). It is published bi-annually and sent to members and subscribers from different parts of the world. IJVET's emphasis is on a broad variety of topics including research, instruction, teaching methods, policy making, and theoretical discourses related to education and training. In turn, International Journal for Research in Vocational Education and Training (IJRVET) was founded in 2013 with the goal of providing full open access to research information in the field and promote global exchange of knowledge in vocational education and training. IJRVET is hosted at the University of Bremen, Germany, and is the official journal of the Vocational Education and Training Network and other European and international professional organizations. 
Journal of Research in Technical Careers

Table 3. Annual Production of Journal Articles in 2008-2017

\begin{tabular}{|c|c|c|c|c|c|c|c|c|c|c|c|c|}
\hline \multirow[b]{2}{*}{ Journal } & \multicolumn{10}{|c|}{ Year } & \multicolumn{2}{|c|}{ Articles } \\
\hline & 08 & 09 & 10 & 11 & 12 & 13 & 14 & 15 & 16 & 17 & Total & Avg. \\
\hline \multicolumn{11}{|c|}{ CTE Interdisciplinary Emphasis } & 210 & 21 \\
\hline - CTER & 13 & 9 & 10 & 11 & 16 & 15 & 14 & 12 & 12 & 12 & 124 & 12.4 \\
\hline - JCTE & 10 & 10 & 14 & 13 & 16 & 3 & 2 & 3 & 3 & 3 & 77 & 7.7 \\
\hline - JRTC $^{1}$ & & & & & & & & & & 9 & 9 & $9.0^{1}$ \\
\hline \multicolumn{11}{|c|}{ CTE Disciplinary Emphasis } & 1,056 & 105.6 \\
\hline - FCSRJ & 21 & 35 & 29 & 30 & 28 & 25 & 28 & 24 & 28 & 23 & 271 & 27.1 \\
\hline - JAE & 47 & 41 & 52 & 58 & 53 & 67 & 71 & 60 & 60 & 79 & 588 & 58.8 \\
\hline - JRBE & 12 & 12 & 12 & 4 & 10 & 10 & 9 & 5 & 5 & 5 & 84 & 8.4 \\
\hline - JTE & 20 & 12 & 10 & 10 & 9 & 12 & 11 & 9 & 9 & 11 & 113 & 11.3 \\
\hline \multicolumn{11}{|c|}{ CTE/Workforce Emphasis } & 937 & 93.7 \\
\hline - CCJRP & 89 & 95 & 80 & 56 & 74 & 89 & 93 & 105 & 78 & 75 & 834 & 83.4 \\
\hline - OJWED & 4 & 15 & 12 & 13 & 14 & 11 & 10 & 7 & 6 & & 92 & 9.2 \\
\hline - WEF & & & & & 7 & & 4 & & & & 11 & 1.1 \\
\hline \multicolumn{11}{|c|}{ International/VET Emphasis } & 1,153 & 115.3 \\
\hline - IJRVET $^{2}$ & & & & & & & 8 & 18 & 12 & 19 & 57 & $14.3^{2}$ \\
\hline - IJAVET $^{3}$ & & & 17 & 18 & 19 & 21 & 20 & 19 & 26 & 22 & 162 & $20.3^{3}$ \\
\hline - IJVET $^{4}$ & & & & 8 & 8 & 13 & 22 & 14 & & 15 & 80 & $11.4^{4}$ \\
\hline - JEW & 24 & 25 & 25 & 28 & 27 & 24 & 30 & 31 & 45 & 60 & 319 & 31.9 \\
\hline - JOTED $_{5}$ & & & & & & 11 & 10 & 9 & 19 & 5 & 54 & $5.4^{5}$ \\
\hline - JVET & 29 & 33 & 33 & 41 & 33 & 36 & 31 & 32 & 26 & 32 & 326 & 32.6 \\
\hline - V\&L & 12 & 13 & 13 & 13 & 16 & 19 & 17 & 17 & 18 & 17 & 155 & 15.5 \\
\hline Total & 281 & 300 & 307 & 303 & 330 & 356 & 380 & 365 & 347 & 387 & 3,356 & 335.6 \\
\hline
\end{tabular}

Note: ${ }^{1}$ Established 2017; ${ }^{2}$ Established 2014; ${ }^{3}$ Established 2010; ${ }^{4}$ Online access since 2011; ${ }^{5}$ Established 2013

Rate of Dissemination. A review of journal production from 2008 to 2017 was conducted to determine the number of issues and articles per year for each journal in Table 2. For journals established later than 2008 , the average production was determined based on the year they were started. The average annual production for each journal is reported in Table 3.

Overall, a total of 3,356 articles were disseminated over the past ten years (2008-2017) for all journals in the field $(n=17)$. Based on this combined total for the period, an average of 336 articles were typically published in a given year in the field. The highest rate of dissemination over the past ten years has been produced by international journals with an emphasis in vocational education and training, with $1,153(34.4 \%)$ of the combined number of articles in this category. Journals with a CTE disciplinary emphasis are the second most productive with a total of 1,056 articles (31.4\%), followed by journals emphasizing CTE/workforce connections with 937 articles (28.0\%). In turn, the three journals emphasizing CTE interdisciplinary issues only contributed to $6.2 \%$ (210 articles) of the combined total production of articles in the same ten-year period.

CTE interdisciplinary emphasis. Regarding journals focusing on interdisciplinary issues in CTE, a combined total of 210 articles were produced in 2008-2017, with an average of 6.5 issues and 21 articles per year (Table 3 ). The production trend is illustrated in Figure 2.
As depicted in Figure 2, the two flagship journals in CTE shared a similar production trend from 2008 to 2012. In 2013, there was a substantial dip in the number produced by JCTE but the journal maintained an average of three articles/year through 2017, while CTER regressed to its mean at around 12 articles a year. In 2015, the Journal of Research in Technical Careers (JRTC) was established and published two issues in 2017 with a total production of nine articles in 2017. In general, CTER produced the bulk of articles in this category accounting for $59 \%$ of the output in this category, followed by JCTE with $37 \%$. Combined, these two journals produced $96 \%$ of all articles with a CTE disciplinary emphasis in 2008-2017.

CTE disciplinary emphasis. The review of dissemination rates by journals with a CTE disciplinary emphasis revealed an average of 12.1 issues a year and a total of 1,056 articles in this category. The publication trend of journals with this emphasis is illustrated in Figure 3 .

Journal of Agricultural Education (JAE) has by far the most productive publication record with an average of 59 articles a year and consistent increases in dissemination rates over the ten-year period reviewed for this analysis. As such, JAE accounted for slightly more than half $(55.6 \%)$ of the publication production in 2008 2017. In contrast, the publication record of other disciplinary journals has been rather consistent but at lower output with Family and Consumer Science 


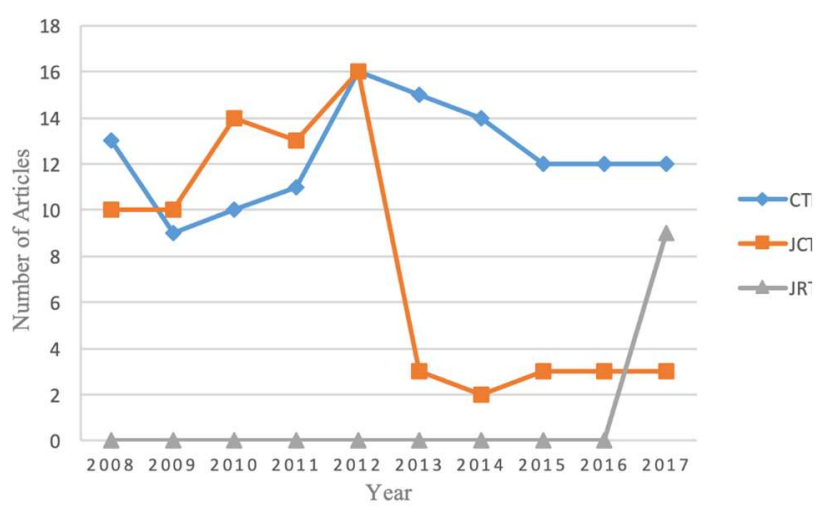

Figure 2. Trend of Annual Publication by Journals with Holistic/Interdisciplinary CTE Emphasis

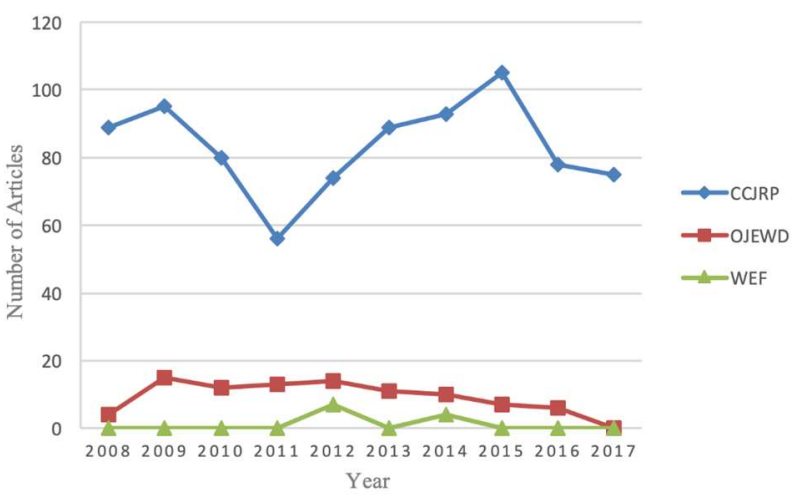

Figure 4. Trend of Annual Publication by Journals with CTE/Workforce Emphasis

Research Journal (FCSRJ) publishing an average of 27 articles per year, and producing about a quarter of the publication output in this category. The publication record of Journal of Technology Education (JTE) and Journal of Research in Business Education (JRBE) has also been consistent albeit at lower rates with an average of 11.3 articles a year for the former and 8.4 for the latter. Combined, JTE and JRBE accounted for 18.7\% of all articles published over the past ten years.

CTE/workforce emphasis. Three journals were identified as having an emphasis on the intersection of CTE and workforce issues (see Table 2). An average of 13.3 issues were produced in a given year in 2008-2017, with a total of 937 articles. As shown in Figure 4, Community College Journal of Research and Practice (CCJRP) had the highest publication output over the past ten years with a total of 834 articles and an average of 83.4 articles/year. Although the journal observed a dip in 2011, the dissemination rate has followed a consistent trend of high productivity during the period of analysis. As such, CCJRP accounted for the bulk of the publication

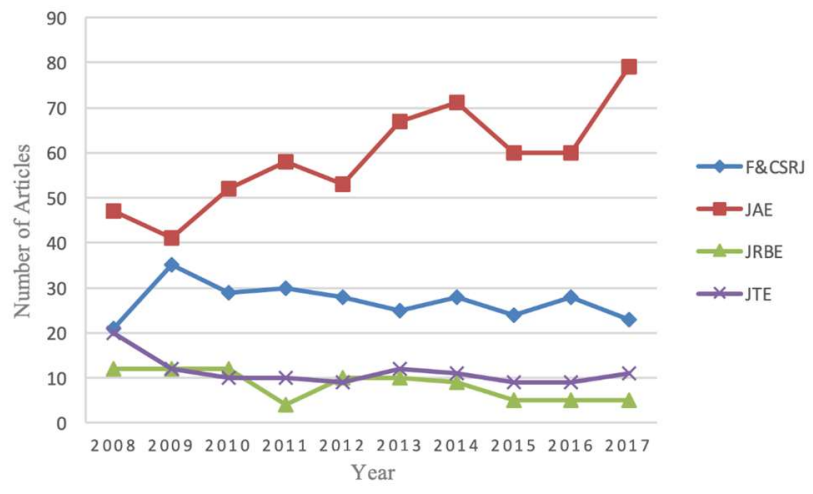

Figure 3. Trend of Annual Publication by Journals with CTE Disciplinary Emphasis

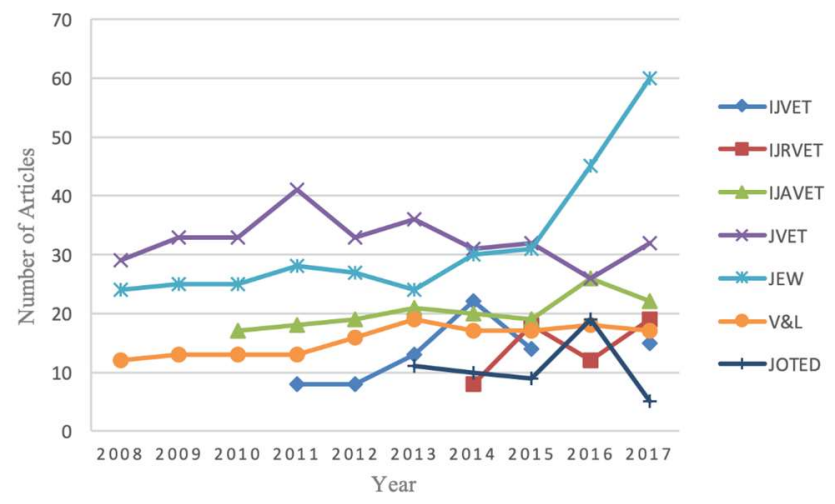

Figure 5. Trend of Annual Publication by Journals with International/VET Emphasis

output in the ten-year period with $89 \%$ of all articles for this category.

By comparison, the publication trend of the other journals in this category exhibited rates of dissemination at a much lower level with a tendency to decrease over time. Online Journal of Workforce Education and Development (OJWED) has an average of 8.2 articles/year, while the Workforce Education Forum (WEF) only published an average of 1.1 articles during the same ten-year period. Combined, OJWED and WEF produced $11 \%$ of all articles in this category in 20082017.

International/VET emphasis. Seven journals were identified as having an international scope with an emphasis in vocational education and training (Table 2). A total of 1,153 articles were produced in 2008-2017, with average of 23.3 issues and 115.3 articles a year. As depicted in Figure 5, there appears to be three tiers of publication in this category, with both Journal of Vocational Education and Training (JVET) and Journal of Education and Work (JEW) producing with an average of more than 30 articles per year (Table 3). Together, these two journals accounted for $56 \%$ of all articles 
published in 2008-2017 for this category. JEW appears to be on the recent rise in terms of production since 2013, while JVET seems to follow a trend around the mean of 32.6 articles/year.

In the second tier of publication output, three journals produced an average of articles/year ranging from 14.3 to 20.3. International Journal of Adult, Vocational Education and Technology (IJAVET) typically produces three issues a year and, although it recorded a spike in production in 2016, overall exhibited a stable output of a mean of 20 articles/year. Similarly, Vocations \& Learning (V\&L) recorded a steady rise in production from 2008 to 2013, but it has remained stable through 2017 around the mean of 15.5 articles/year. Likewise, a relatively new publication, International Journal for Research in Vocational Education and Training (IJRVET), established in 2014, has begun to develop a trend in production around a mean of 14.3 articles per year. Combined, these three journals accounted for about a third (32.4\%) of the total publication output in 2008-2017. Finally, the International Journal of Vocational Education and Training (IJVET) and the Journal of Technical Education (JOTED), were noted at a relatively lower tier of dissemination around an average of 11 articles per year. The total output of IJVET and JOTED represented $11.6 \%$ of all articles published in the ten-year period of interest.

All in all, about two-thirds $(66 \%)$ of the dissemination of research information in the field can be tracked to sources in the United States, with a total of 2,203 articles disseminated by ten journals at an average of 220 articles per year in 2008-2017. About a third $(34 \%)$ of dissemination of research information can be accounted for by journals with an international scope and emphasis in vocational education and training, as reported above.

\section{Discussion and Conclusions}

Based on the analysis of academic journals in the field of CTE and trends in dissemination rates, diffusion of information follows the model underlying the review of related data (Brownson et al., 2018; Weaver \& Shannon, 1963). At the core of the model is a considerable flow of research information in the United States and abroad, channeled electronically for anytimeanywhere access through paid subscription or-open access. As such, the diffusion process fits the premises underlining the communication of innovative practices (or research information) over time to inform interested audiences (Brownson et al., 2018; Rogers, 2003). In that regard, it has been noted that innovation ideas have to be relevant by members of a community if they are likely to be adopted (King et al., 2003; Rogers, 2003). To that end, it appears that the typology of journals in the field (journal source) aligns with this notion given the different emphasis featuring CTE interdisciplinary issues, disciplinary foci, CTE/workforce connections, and international/VTE implications. That is, with an estimated average of 336 articles published in a given year and 17 journals catering to different audiences in the field, it appears the dissemination of research information is robust given the size of the field in the United States and abroad. Moreover, recently established journals appear to enhance the pool of publication outlets in the field given the publication trends reported in the results.

Further, the interaction between the type of journal source and audience discussed in the literature aligns with their implied roles in the model used in this study (Figure 1). In the United States it is clear that dissemination of research information in the field is still closely mediated by journals representing disciplinary audiences in agricultural, business, family and consumer science, and technology education. As such, the rate of dissemination by disciplinary journals in the United States is comparable to international rates. Internationally, the field continues to be recognized as vocational education and the emphasis of journals is holistic, focusing on issues relevant to the field in general, albeit from different vantage points.

All in all, the results of this review also align with literature related to the question about where to publish. The premises for finding the right fit for a manuscript is related to identifying the proper channel (journal) to reach the intended audience (Lawrence, 2001; Tenopir et al., 2009; Vasishta, 2013). In this case, the typology identified through this review may represent a useful tool for the identification of channels (journal sources) targeting audiences interested in CTE interdisciplinary issues, disciplinary topics, CTE/workforce connections, and international/vocational education and training. Understanding the journal emphasis, authors and readers can sort out decisions for submission of manuscripts or reading queries.

The results of journal publication data also reaffirmed the collective role of publication outlets as contributors to the common goal of building a shared knowledge base in the field through reliable and steady rate of production. That is, in addition to clear identification of journal sources, information seeking relies heavily on the consistent availability of articles and a steady dissemination rate over time (Flanagan, 2013; Gasparyan et al., 2017). In a small field such as CTE, the rate of dissemination over a given period of time may yield a point of consideration comparable to an impact factor when assessing journal performance.

In conclusion, this analysis over the past ten-year period suggests a robust pool of journals mediating the dissemination of research information in the field. Although the exclusion of some journals may be disputed, at least 17 journals were identified as making a direct contribution to diffusion of research in the United States and internationally. Further, a consistent rate of dissemination was observed as a whole but was variable for individual journals in 2008-2017. As such, small but steady increases in publication rates were consistently 
observed over time - from a collective standpoint - with growth from an average of 281 articles in 2008 to 387 in 2017. The increases may be due, perhaps, to new journals being established over the past decade. In addition, it appears the current journals are representing different CTE audiences in the United States and internationally and are thus providing appropriate dissemination channels in the field. Finally, the results of this review also point to the possible use of consistency in dissemination rates over time as a potential alternative indicator of journal impact in a small academic field (Flanagan, 2013; Gasparyan et al., 2017). If so, the rate of dissemination over a given period of time can be used as an indicator of journal impact for the included journals. The caveat here is that, although it is helpful to count on predictable publication schedules and quantity of articles published in a year, the scholarly quality of a journal should not be measured on quantity alone. Journal quality was an issue discussed at length at the business meeting of the Career and Technical Education Special Interest Group at the 2018 Meeting of the American Educational Research Association (Gordon et al., 2018), and is a conversation we should continue in the field to ensure the vitality and quality of our diffusion model.

Note: This article was revised on December 10, 2018, to correct errata on page 9 re: $J A E$.

\section{References}

Association for Career and Technical Education. (2018). CTE today! Retrieved from: https://www.acteonline .org/wp-content/uploads/2018/03/CTE Today Fact -Sheet January2018.pdf

Bailey, T. R., Smith Jaggars, S., \& Jenkins, D. (2015). Redesigning America's community colleges: A clearer path to student success. Cambridge, Massachusetts: Harvard University Press.

Brownson, R. C., Eyler, A. A., Harris, J. K., Moore, J. B., Tabak, R. G. (2018). Getting the word out: New approaches for disseminating public health science. Journal of Public Health Management and Practice, 24(2), 102-111. https://doi.org/10 .1097/PHH.0000000000000673

Creswell, J. W. (2018). Research design: Qualitative, quantitative, and mixed methods approaches. Thousand Oaks, CA: Sage Publications.

Flanagan, J. (2013). Editorial: Journal factors and their relevance to journal quality. International Journal of Nursing Knowledge, 24(3), 113-114.

Garfield, E. (2006). The history and meaning of the journal impact factor. Journal of the American Medical Association, 295(1), 90-93.

Gasparyan, A. Y., Nurmashev, B., Yessirkepov, M., Udovik, E. E., Baryshnikov, A. A, \& Kitas, G. D. (2017). The journal impact factor: Moving toward an alternative and combined scientometric approach. Journal of Korean Medical Science, 32(2):173-179.

Gordon, H. R. D. (2014). The history and growth of career and technical education in America (4th ed.). Prospect Heights, IL: Waveland Press.

Gordon, H. R. D., Bartlett, J. E., Lasonen, J. L., Hernandez-Gantes, V. M., Martinez, L. K., \& Martin, B. A. (2018, April). Journal impact factors $(J I F)$ : Implications for career and technical educators and related professionals. Panel presentation conducted at the American Educational Research Association, New York, NY.

Gordon, H. R. D., \& Godbey, S. (2017). From the Editors Vol. 1, Iss. 1. Journal of Research in Technical Careers, 1(1). https://doi.org/10.9741 12578-2118.1009

Great Schools Partnership. (2014). The glossary of education reform for journalists, parents, and community members: Career and technical education. Retrieved from: https://www.edglossary .org/career-and-technical-education/

Green, L. W., Ottoson, J. M., Garcia, C., \& Hiatt, R. A. (2009). Diffusion theory, and knowledge dissemination, utilization, and integration in public health. Annual Review of Public Health, 30, 151174.

Herie, M., \& Martin, G. W. (2002). Knowledge diffusion in social work: A new approach to bridging the gap. Social Work, 47, 85-95.

Hernandez-Gantes, V. M. (2016). College and career readiness for all: The role of career and technical education in the US. In D. Wyse, L. Hayward, \& J. Pandya (Eds.), SAGE handbook of curriculum, pedagogy and assessment (Vol. 2, pp. 674-689). London: SAGE.

Kaminski, J. (2011). Diffusion of innovation theory. Canadian Journal of Nursing Informatics, $6(2)$.

King, D. W., \& Tenopir, C. (2001). Using and reading scholarly literature. In M.E. Williams (Ed.), Annual review of information science and technology (pp. 423-477). Medford, N.J.: Information Today.

King, D.W., Tenopir, C., Hansen Montgomery, C., \& Aerni, S. E. (2003). Patterns of journal use by faculty at three diverse universities. $D$-Lib Magazine, 9(10). https://doi.org/10.1045/october2003-king

Lawrence, S. (2001). Free online availability substantially increases a paper's impact. Nature, 411, 521. https://doi.org/10.1038/35079151

Loeb, S., Dynarski, S., McFarland, D., Morris, P., Reardon, S., \& Reber, S. (2017). Descriptive analysis in education: A guide for researchers. (NCEE 2017-4023). Washington, DC: U.S. Department of Education, Institute of Education Sciences, National Center for Education Evaluation and Regional Assistance.

McGuigan, G. S., \& Russell, R. D. (2008). The business of academic publishing: A strategic analysis of the 
academic journal publishing industry and its impact on the future of scholarly publishing. Electronic Journal of Academic and Special Librarianship, 9(3).

Oermann, M., \& Shaw-Kokot, J. (2013). Impact factors of nursing journals: What you need to know. Journal of Continuing Education, 44(7), 293-299. https://doi.org/10.3928/00220124-20130501-14

Rogers, E. (2003). Diffusion of innovations (5th edition). New York: Free Press.

Rojewski, J. W., \& Domenico, D. M. (2004). The arts and politics of peer review. Journal of Career and Technical Education, 20(2), 41-54.

Schaffner, A. C. (1994). The future of scientific journals: Lessons from the past. Information Technology and Libraries, 13(4), 239.

Solomon, D. J. (2007). The role of peer review for scholarly journals in the information age. Journal of Electronic Publishing, 10(1). https://doi.org/10 .3998/3336451.0010.107

Tenopir, C. (2003). Use and users of electronic library resources: An overview and analysis of recent research studies. Washington, DC: Council on Library and Information Resources.

Tenopir, C., \& King, D. W. (2000). The use and value of scholarly journals. Presented at the 63rd Annual Meeting of the American Society for Information Science. Retrieved from: http://works.bepress.com /carol tenopir/48/
Tenopir, C., King, D. W., Edwards, S., \& Wu, L. (2009). Electronic journals and changes in scholarly article seeking and reading patterns. ASLIB Proceedings, 61(1), 5-32. https://doi.org/10 $.1108 / 00012530910932267$

Vasishta, S. (2013). Dissemination of electronic journals: A content analysis of the library websites of technical university libraries in North India. The Electronic Library, 31(3), 278-289.

Vogela, R., Hattke, F., \& Petersen, J. (2017). Journal rankings in management and business studies: What rules do we play by? Research Policy, 46, 1707-1722.

Ware, M., \& Mabe, M. (2015). The STM Report: An overview of scientific and scholarly journal publishing. Copyright, Fair Use, Scholarly Communication, etc., 9. http://digitalcommons.unl .edu/scholcom/9

Weaver, W., \& Shannon, C. (1963). The mathematical theory of communication. Champaign, IL: University of Illinois Press. 